\title{
Trésor, mémoire, merveilles. Les objets des églises au Moyen Âge
}

\section{Philippe Cordez}

\section{OpenEdition}

\section{Journals}

Édition électronique

URL : http://journals.openedition.org/ifha/179

DOI : 10.4000/ifha.179

ISSN : 2198-8943

\section{Éditeur}

IFRA - Institut franco-allemand (sciences historiques et sociales)

\section{Édition imprimée}

Date de publication : 6 février 2011

Pagination : 142-145

ISSN : 2190-0078

\section{Référence électronique}

Philippe Cordez, "Trésor, mémoire, merveilles. Les objets des églises au Moyen Âge », Revue de l'IFHA [En ligne], 3 | 2011, mis en ligne le 10 février 2012, consulté le 25 avril 2019. URL : http:// journals.openedition.org/ifha/179; DOI : 10.4000/ifha.179

Ce document a été généré automatiquement le 25 avril 2019

(CIFHA 


\title{
Trésor, mémoire, merveilles. Les objets des églises au Moyen Âge
}

\author{
Philippe Cordez
}

\section{NOTE DE L'ÉDITEUR}

Philippe Cordez a soutenu sa thèse de doctorat en histoire et civilisations et en histoire de l'art, en cotutelle entre l'École des hautes études en sciences sociales (Paris) et l'université Humboldt (Berlin), sous la direction de Jean-Claude Schmitt et de Horst Bredekamp, le 18 octobre 2010. Il a bénéficié d'aides à la mobilité de la MHFA et du CIERA. Ancien allocataire de recherche (2003-2006), wissenschaftlicher Mitarbeiter au Kunstgeschichtliches Seminar de l'université de Hambourg (2007-2009), il est depuis 2009 wissenschaftlicher Assistent au Kunsthistorisches Institut in Florenz - Max-Planck-Institut (Italie).

Cette enquête fait l'hypothèse que le christianisme a profondément marqué la "culture matérielle » de l'Occident, et entend contribuer à éclairer ce phénomène en portant l'attention sur les « objets » et les «trésors » des églises médiévales. Ses points de départ et d'arrivée, développés en introduction et en conclusion, concernent le statut des objets dans les collections modernes et contemporaines, c'est-à-dire leur perte de fonction et leur remise en scène dans les musées, et leur rôle dans la pratique de l'analyse et de l'interprétation historique.

Une étude des «trésors d'églises » du Moyen Âge apparaît cruciale dès lors que l'on constate que l'institution occidentale du musée en est issue pour bien des aspects déterminants, mais n'a pas pour autant reconnu cet héritage. Un transfert de sacralité a eu lieu, la modernité refoulant ses propres cultes d'objets, et les projetant sur d'autres cultures sous les noms d'«idolâtrie" et de «fétichisme", de manière à pouvoir développer sa notion d'un "art » autonome ${ }^{1}$. Les musées se réclament plus volontiers jusqu'à aujourd'hui d'autres ancêtres, tels les studioli des humanistes, les cabinets des Lumières ou les fondations révolutionnaires, qui peuvent servir de garants à leur 
ambition scientifique et démocratique. Mais le développement d'un marché de l'art global et la réorientation postcoloniale de nombreux musées d'anthropologie montrent que les musées, instruments majeurs des politiques culturelles contemporaines, ne pourront développer toutes leurs potentialités qu'avec une pleine conscience de l'histoire longue des pratiques de l'objet privilégié en Occident ${ }^{2}$.

Les historiens également sont en prise avec la culture chrétienne lorsqu'ils utilisent, avec la notion de « source », un concept suggérant une révélation et une régénération, tout en rejetant dans l'ombre les aspects matériels, le processus d'établissement de l'évidence et le chercheur lui-même $e^{3}$. La question des "objets" de l'historien - ceux qu'il soumet à l'analyse ou plus largement ses «objets d'étude »- pose le problème du rapport sujet/ objet dans la production scientifique de l'«objectivité » historique. La conception de ce qu'est un objet est soumise à des variations historiques, impliquant des régimes de temporalité variés qu'il importe de mettre en évidence. On s'est intéressé aux objets mobiliers des églises médiévales en observant ceux qui sont conservés, mais aussi les textes et les images qui en faisaient état, les inspiraient ou déterminaient leur appréhension: mettre au jour leurs rapports respectifs permet de saisir les uns et les autres dans les mouvements qui leur étaient assignés, et de décrire leurs enjeux en fonction des questions posées.

Les trois parties du travail constituent autant de contributions à une réflexion sur la pratique des objets dans les musées et chez les historiens d'aujourd'hui. La première considère l'histoire de la figure du "trésor ", qui qualifie globalement les objets des églises tout en désignant des réalités immatérielles, et demeure importante pour la culture occidentale ${ }^{4}$. Ceci est l'occasion de préciser le rôle attribué aux objets ecclésiastiques, et par-delà ces derniers à toute richesse, circulante ou thésaurisée, par les clercs réfléchissant sur la société chrétienne, l'institution de l'Église et les échanges matériels et spirituels. Tout au long du Moyen Âge, la question des objets et de leurs usages a suscité des débats, vivement polémiques ou profondément théoriques, souvent dans des situations de crise et avec des conséquences concrètes, dans les domaines de l'ecclésiologie, du droit, de la théologie, de la pastorale, ou de ce que l'on appellera plus tard l'économie. Après une mise en place par les Pères de l'Église, des moments d'innovation furent la réforme carolingienne, avec l'introduction de la notion de «trésor d'église» rapprochant le pouvoir impérial des institutions ecclésiastiques, puis l'urbanisation des XIIe et XIIIe siècles, avec l'invention civile d'un trésor comme «bien commun» et celle, scolastique, du «trésor des grâces" où étaient puisées les indulgences, avant que le thème ne joue encore un rôle central dans les polémiques confessionnelles du XVIe siècle.

La seconde partie explore la dimension mémorielle des objets ecclésiastiques médiévaux, et ainsi la pratique occidentale de conserver des objets durant plusieurs siècles dans des institutions. Le rôle de l'écriture et du texte apparaît comme central, tant dans la revendication d'authenticité des objets que dans leur administration et dans leur mise en scène. La gestion et la médiation des reliques ${ }^{5}$, parfois assemblées en collections, sont décrites à travers la fonction et les structures de leurs étiquettes et inventaires. Le processus de la construction des objets de mémoire, d'ordre narratif et matériel à la fois, est reconstitué à partir des adaptations locales du «bâton de saint Pierre» et du "prépuce du Christ», objets spécialement significatifs pour la culture chrétienne. L'interprétation des dons de matériel d'échecs, ce "jeu de société », montre le rôle de ces 
objets dans l'expression et la commémoration des rapports entre les églises et certains acteurs de la société féodale, en particulier au XIe siècle.

La troisième partie est consacrée aux objets qui doivent leur statut à une origine végétale

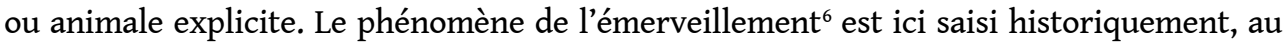
sens d'une rhétorique mise en œuvre à travers reliquaires, supports d'exempla, ex-voto ou encore trophées. đuufs, noix et coquilles surdimensionnés, cornes de licorne, os de géant, dragons, griffes de griffon ou dents de baleine constituent autant de types d'objets pour la conception desquels les éléments narratifs jouent souvent un rôle décisif, et dont l'histoire est retracée en une série d'analyses particulières. On constate autour de 1200 l'instauration de ce genre d'objets, qui furent exposés publiquement dans les églises avant d'être soumis à la critique des « naturalistes » de l'époque moderne, lesquels en rejetèrent certains et réunirent les autres sous l'appellation commune de naturalia dans leurs cabinets, puis leurs musées ${ }^{7}$.

\section{NOTES}

1. Wilhelm Pietz, « Fetish » in: Robert S. Nelson, Richard Shift (dir.), Critical Terms for Art History, Chicago: Univ. of Chicago Press, 1996, p. 197-207; Hartmut Böhme, Fetischismus und Kultur. Eine andere Theorie der Moderne, Hamburg : Rowohlt, 2006.

2. Catherine Ballé, Dominique Poulot, Musées en Europe. Une mutation inachevée, Paris : La Documentation française, 2004 ; Élise Dubuc, Laurier Turgeon, « Musées et premières nations. La trace du passé, l'empreinte du futur » in : Id. (dir.), Anthropologie et sociétés, 28/2, 2004, p. 7-18; Thierry Dufrêne, Anne-Christine Taylor (dir.), Histoire de l'art et anthropologie, 2009, http://actesbranly. revues.org/60.

3. Thomas Rathmann, Nikolaus Wegmann (dir.), «Quelle». Zwischen Ursprung und Konstrukt. Ein Leitbegriff in der Diskussion, Berlin : Schmidt, 2004.

4. Lucas Burkart et alii, (dir.), Le Trésor au Moyen Âge. Discours, pratiques, objets, Firenze : Sismel (Micrologus' Library, 32), 2010.

5. Je me permets de renvoyer à mon bilan historiographique : « Les reliques, un champ de recherche. Problèmes anciens et nouvelles perspectives » in: BullMHFA, 43, 2007, p. 102-116.

6. Jacques Le Goff, « Le merveilleux dans l'Occident médiéval » [1re éd., 1978], rééd. in : Id., Un autre Moyen Âge, Paris: Gallimard, 1999, p. 455-476; Caroline Walker Bynum, «Wonder » in : American Historical Review, 102/1, 1997, p. 1-26.

7. Lorraine Daston, Katharine Park, Wonders and the Order of Nature, 1150-1750, New York : Zone Books, 1998. 